PLATELET RESPONSE TO IMMUNOLOGICAL INJURY. J.G. White, R.M. Condie, and G.H.R. Rao. Univ. of Minn. School of Med., Mpls., Minn.

Platelets are susceptible to immunological destruction, but the nature of the immune lesion has not been defined. Biochemistry, physiology, freeze-etching and electron microscopy were used to detect antibody induced injury. Antiserum (AS) was raised in a horse by repeated I.M. injections of glutaraldehyde fixed human platelets. Absorbtion with PPP removed non-specific activity of AS. The AS caused release of serotonin to a dilution of $1: 10,000$ without producing ultrastructural damage. AS stimulated aggregation in stirred C-PRP to a dilution of $1: 1000$. Aggregates resembled those produced by collagen. Lactic dehydrogenase was not discharged by dilutions greater than 1:10. Dilutions to $1: 100$ caused platelet lysis and produced characteristic membrane lesions visible in replicas of freeze-etched cells. The lesions consisted of $80 \mathrm{~A}^{\circ}$ particles in semi-circular or circular arrangements located on the inner surface of the outer leaflet, but not on the outer surface of the inside half of the split lipid bilayer. Complement was required for development of the lesions. Anti-lymphocyte serum strongly active against human platelets produced similar lesions, but antisera to rabbit platelets raised in a goat did not. The results indicate that specific, complement-dependent lesions are produced in platelet mem-branes by lytic concentrations of AS. Smaller amounts of AS or other anti-platelet substances may cause aggregation and release serotonin without producing specific lesions.

A NEW SYNDROME OF CONGENITALLY DEFECTIVE PHAGOCYTOSIS.

Dana M. Whitten, Barbara I. Warren, Uma S. Rai, and Thomas F. Necheles (Intr. by Sydney S. Geliis). Tufts Univ. School of Medicine and N.E. Medical Center Hospitals, Boston. Siblings of opposite sex experienced frequent and severe bacterial infections, usually respiratory, from early in childhood. The girl's infections were often accompanied by acute and massive Coomb' positive hemolytic anemia, as well as marked hepatosplenomegaly, both of which responded to steroid therapy. Immunoglobulin levels were slightly low but total hemolytic complement, $C^{\prime} 3$ and antibody production were normal. Her brother has persistent hepatosplenomegaly with mild anemia and repeated severe pneumonia usually due to Pseudomonas. Routine immunologic studies were also normal. Phagocyte function in terms of particle uptake and bacterial killing in both is normal, whereas their serum fails to support the phagocytosis of bacteria by normal white cells in vitro. This defect is corrected by the addition of normal serum to the assay, but not by heat inactivated serum, and opsonin activity of normal serum is not inhibited by patients' serum. No defect can be identified in the parents. The opsonizing deficiency is most marked with gram negative bacteria with 80 to $135 \%$ of initial bacteria surviving at 2 hours, the majority extracellular, as compared to less than $10 \%$ survival using normal serum. Present studies suggest a defect in the alternate pathway of complement activation. The patients have been essentially well for several months while receiving infusions of fresh frozen plasma twice monthly.

THE BIOLOGIC SIGNIFICANCE OF THE THIRD COMPONENT OF COMPLEMENT (C3) IN NONIMMUNE HOST DEFEINSES. Jerry A. Winkelstein, Mary Ruth Smith and Hyun S. Shin. Johns Hopkins Univ. Sch. of Med., Dept. of Pediatrics and Microbiology, Baltimore. (Intro. by David Hi. Carver) Studies performed in vitro have demonstrated that C 3 acts as an opsonin when activatea to $C 3 b$ and fixed to bacteria. In order to investigate the significance of $\mathrm{C} 3$ as an opsonin in vivo the following experiments were performed in normal, nonimmune mice.

Mice were totally depleted of serum C3, as measured in a hemolytic assay, by the injection of cobra venom factor (COVF). Concurrent with the $c 3$ depletion their serum opsonizing activity decreased to a level less than 208 of normal. When mice were challenged with an intraperitoneal injection of pneumococci(Pn) immediately after the CoVF treatment, the $\mathrm{LD}_{50}$ was $1.8 \times 10^{6}$ as compared to $6.8 \times 10^{7}$ in saline treated control animals $(P<0.05)$. When the Covf was given only 6 hours after the Pn challenge the LD $\mathrm{LD}_{5}$ was the same as in the control mice. If Pn were preopsonized in vitro with nonimmune mouse serum and then injected into CoVF treated animals, the $\mathrm{LD}_{50}$ was the same as that in control animals.

These studies demonstrate that there is a biologically significant in vivo role for $C 3$ as an opsonin in the nonimmune host's defense against bacterial infection and that that role is most significant in
INDUCTION OF ABNORNAL IMMUNOPOIESIS BY PERSISTENT EMBRYONIC VIRAL INFECTION. T. Yamauchi, J.V. St. Geme, Jx., H.L. Martin, D.C. Heiner and M.D. Cooper. UCLA Sch. Med. llarbor Gen. Hosp. and Univ. Ala. Ned. Ctr., Depts. Ped., Torr. and B1rmingham.

Infection of 16-hour-old chicken embryos with mumps virus produced an initial decrease of both plasma 'IgM and IgG in poults with delayed maturation of normal IgG synthesis. Despite hypogammaglobulinemia, specific antiviral neutralizing antibody first appeared one week after disappearance of virus from 7-day-old hatchling chicks.

Intramuscular inoculation of 19-day-old chicks with heterologous erythrocytes elicited significantly $(P<.01)$ lower titers of agglutinins in embryonically-infected birds with a delay in transition of $19 \mathrm{~S}$ to $7 \mathrm{~S}$ antibody. Secondary antibody surge in experimental birds was also significantly $(\mathrm{P}<.02)$ less than controls with continued predominance of 195 antibody.

Induction of cell-mediated immunity by footpad inoculation of 46-day-old birds with diphtheria-tetanus toxoid in complete Freund's adjuvant failed to discern suppression of T-cell function in previously infected chicks.

Virus, detected in high titer throughout embryonic development, declined in the bursa of Fabricius prior to hatch. Although bursae of infected 7-day-old birds contained a silghtly greater population of IgN-producing lymphold cells than controls, distribution of $\mathrm{IgG}$ in bursae of experimental chlcks was strikingly reduced. Con'sistent with persistent embryonic infection and altered bursal function, Igk alone was observed in spleens of infected chicks only.

HISTAMINE METABOLISM IN CELLS OF THE ALLERGIC RESPONSE. Robert S. Zeiger and Harvey R. Colten. Harvard Med. Sch. Child. Hosp. Med Ctr. Dept. of Ped. Boston.

We have developed sensitive and rapid assays to investigate histamine synthesis (histidine decarboxylase activity) (HD) and degradation (histaminase activity) during specific allergen triggered histamine release. HD activity was determined in isolated mast cells and mixed human leukocytes using $2{ }^{14} \mathrm{C}$ histidine (50uM, 0.5uc) as substrate. Synthesized histamine was separated by thin layer chromatography on cellulose sheets and quantitated in cut sections of chromatograms by liquid scintillation spectrometry. In isolated mast cells (>988pure) HD activity was linear for at least $6 \mathrm{hr}$. with an activity of $20 \mathrm{ng}$ histamine synthesized $/ 10^{6}$ mast cells/hr. Histaminase activity was determined by a similar thin layex chromatographic technique. The degradative products formed from the interaction of soluble cell sonicates and $2-14 \mathrm{C}$ histamine (8uM, 0.1uc) were quantitated by scintillation spectrometry. Histaminase activity was undetectable in "mononuclear cell fractions" (>988 lymphocytes, monocytes, basophils) but was present in a granulocyte fractions (>988 neutrophils and eosinophils) of human leukocytes. In granulocytes, histaminase activity was associated principally with eosinophils. In eosinophil-rich fractions ( $95 \%$ pure), histaminase activity was linear for at least $5 \mathrm{hr}$. with an activity of 50 pmol/5xlo6 eosinophils/hr. These data suggest that the human eosinophil may modulate the allergic response by neutralizing histamine during allergen stimulated histamine release.

\section{INFECTIOUS DISEASE}

ACUTE EPIGLOTTITIS - AN ACUTE SURGICAL EMERGENCY. James W. Bass, Russe11 W. Steele and Robert A. Wiebe. Dept. of Pediatrics, Tripler Army Medical Center, Honolulu, Hawail.

A review of 97 patients with acute epiglottitis: 83 , a retrospective study and 14 , a prospective experience of the authors is presented to clarify some of the common misconceptions regarding the presentation, clinical course, and management of this disorder. It is a relatively rare, life threatening infection of infants and preschool children, but also occurs in adults. It is frequently referred to as "Hemophilus influenzae croup epiglottitis" which is misleading as croup is usually not present in these patients; and, though $\mathrm{H}$. influenzae is the most common causative organism, other pathogens have been implicated. The course of acute epiglottitis is radically different from that of the more common viral subglottic croup syndromes in that these patients often have rapidly progressive and frequently abrupt, complete airway obstruction. An assured airway is mandatory in their management. Since nasotracheal intubation should not be undertaken without provisions for imnediate surgical intervention, acute epiglottitis should always be considered an acute surgical emergency. 